WSRC-RP-92-371, REV 0

\title{
BASIC DATA REPORT: CANISTER PENETRATION SYSTEM WITH RELATIVE HUMIDITY AND PRESSURE SENSORS (U)
}

by J.R. Harbour

WSRC-RP-92-371

Westinghouse Savannah River Company

Savannah River Site

Aiken, South Carolina 29808

Other Authors:

This paper was prepared in connection with work done under Contract No. DE-AC09-89SR18035 with the U. S. Department of Energy. By acceptance of this paper, the publisher and/or recipient acknowledges the U.S. Government's right to retain a nonexclusive, royalty-free license in and to any copyright covering this paper, along with the right to reproduce and to authorize others to reproduce all or part of the copyrighted paper.

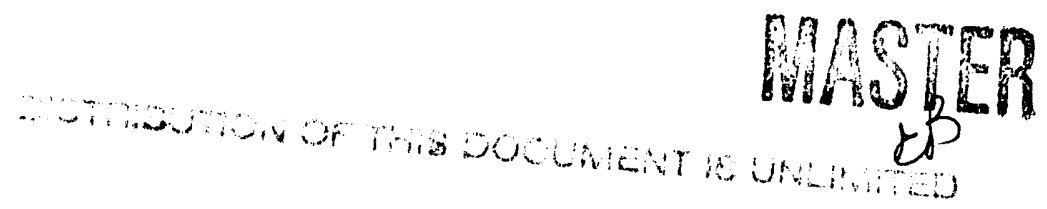




\section{DISCLAIMER}

This report was prepared as an account of work sponsored by an agency of the United States Government. Neither the United States Government nor any agency thereof, nor any of their employees, makes any warranty, express or implied, or assumes any legal liability or responsibility for the accuracy, completeness, or usefulness of any information, apparatus, product, or process disclosed, or represents that its use would not infringe privately owned rights. Reference herein to any specific commercial product, process, or service by trade name, trademark, manufacturer, or otherwise does not necessarily constitute or imply its endorsement, recommendation, or favoring by the United States Government or any agency thereof. The views and opinions of authors expressed herein do not necessarily state or reflect those of the United States Government or any agency thereof.

This report has been reproduced directly from the best available copy.

Available to DOE and DOE contractors from the Office of Scientific and Technical Information, P.O. Box 62, Oak Ridge, TN 37831; prices available from (615) 576-8401, FTS 626-8401.

Available to the public from the National Technical Information Service, U.S. Department of Commerce, 5285 Port Royal Rd., Springfield, VA 22161. 
WESTINGHOUSE SAVANNAB RIVER COMPANY WSRC-RP-92-371 SAVANNAE RIVER LABORATORY REVISION 0

MEMORANDOM

\author{
KEYWORDS : Punch \\ system, pressure, \\ relative humidity, \\ basic data, \\ Retention: \\ Lifetime
}

MARCB 18, 1992

TO: D. J. Pak and T. J. Miller, 723 A

FROM: J. R. Barbour, 773-43A

BASIC DATA REPORT
CANISTER PENETRATION SYSTEM NITH
RELATIVE HOMIDITY AND PRESSURE SENSORS

(ס)

DESIGN CATEGORY: PRODOCTION SUPPORT

CC: M. J. Plodinec, 773-A

E. พ. Holtzscheiter, 773-A

R. E. Mottel, 773-43A

P. E. Lowe, 773-66A

C. B. Payne, 704-24s

RECORDS (4)

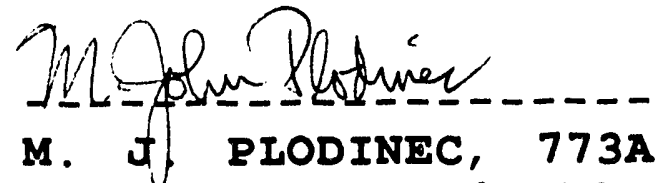

Authorized Derivative Classifier 
PAGE

3

3

4

4

5

5

7

7

7

8

8

8

8

8

8

8

9

9

9

10
1.0

2.0

2.1

2.2

3.0

4.0

5.0

6.0

7.0

8.0

9.0

10.0

11.0

12.0

13.0

14.0

15.0

16.0

17.0

18.0
TABLE OF CONTENTS

Preliminary Process Hazards Requirements

General Description of the Items

Additional Requirements

Responsibilities

Purpose of the Items

Basic Functions of the Parts.

Waste Disposal, Environmental

Protection, Permitting and other

Regulatory Requirements.

Safety and Fire Protection Requirements

Raw Materials, Storage and Tank Farm Facilities.

Utilities

Service Facilities and Isolation Requirements

Site and General Facilities

Computer Requirements.

Extra Machinery Spare Parts

Quality Assurance Requirements

Codes and Standards

Decommissioning

Appendices

References

Figures 


\subsection{Preliminary Process Hazards Requirements}

Not required according to the criteria presented in SRL Engineering Design Procedures Manual, DPSTOM-48, SRL DMP QA 3-3, page 11 and in the GTG Procedures 3.1 (rev 2), section 4.6 .1 .

\subsection{General Description of the Items}

This work originates from a task assignment ${ }^{1}$. This basic data report is for design and fabrication of a canister penetration system for use in these experiments. The basic system was designed and fabricated as a result of a previous task assignment ${ }^{2}$ and three associated task plans ${ }^{3-5}$. The new system, which will be used on canistered waste forms produced during the DWPF Start up Test Program, will be a modification of the previous system ${ }^{6}$. Hence the seven items identified in the next paragraph have been previously designed, fabricated, and tested but will be required as part of the overall system.

The canister penetration system to be designed and fabricated shall consist of (1) a device which can penetrate the canister above the glass line while preventing the mixing of the air within the canister with the air in the environment, (2) a sensor for measuring the relative humidity and dew point of the air within the canister, (3) a sensor for detecting the pressure of the system before penetration and the pressure of the canister and system after penetration, (4) a vacuum system for evacuating the canister penetration system, (5) a connecting port to a mass spectrometer for on line analysis of the air within the free volume, (6) a number of valves and joints (fittings) which make up the interconnecting plumbing, and (7) a calibrated container for use in measuring the free volume. All of these items are deliverables.

The major focus of this design task is to modify six canisters, prior to glass filling, in order to provide for linkage with the above system after glass filling. This linkage shall not involve welding or drilling. The modification of the canister shall be such that it does not interfere with normal operations as the canister 
proceeds through the DWPF. The modified canisters shall be leaktested to ensure that the leakrate is less than $2 \mathrm{x}$ $10^{-7} \mathrm{~atm} \mathrm{cc} / \mathrm{sec}$ for helium.

It may be necessary to connect this system to canisters which have not been mouified. In this case, it will be necessary to connect to and penetrate the canisters as reported in the previous set of experiments. Therefore any items necessary to accomplish this must also be provided.

\subsection{Additional Requirements}

A measurement of free volume is important for sealed canisters. The system developed for measuring the free volume from before shall be used.

An additional requirement is that sample bottles are available such that they can be attached to the canister penetration system in order to obtain a gas sample of the air within the free volume. This implies that the sample bottle can be evacuated, filled, and after closure, removed from the system and stored.

The canister penetration system needs to be extremely clean. This applies for the sensors and any other parts which will come in direct contact with the gas that occupies the free volume of the canisters.

The tap which EES envisaged for modification of the canisters must be able to withstand temperatures up to $5000^{\circ} \mathrm{C}$ and frit blasting.

\subsection{Responsibilites}

EES is responsible for design and fabrication of the penetration system, associated sample bottles, and modification of six DWPF canisters. EES will also take part in the actual acquisition of data by attaching the system after glass filling, and by penetrating the canister. It is the responsibility of ADS to carry out the analysis of the gas with mass spectrometry. TNX operations will assume certain responsibilities including canister handling and transport. Identification of the 
six canisters for tap insertion will be the responsibility of C. H. Payne and J. R. Harbour.

\subsection{Purpose of the Items}

This system will be used for measuring the relative humidities, corresponding dew points, internal gas pressure, and the chemical composition of the gas occupying the free volumes of the sealed canisters from six canisters. Chemical composition will also be accomplished through an on-line mass spectrometer. The relative humidity and pressure will be monitored by sensors. This data will determine whether free liquid, free gas, or organics exist within the canister. The results will be used to demonstrate compliance with the WAPS (Waste Acceptance Preliminary Specifications), and will be included in the WQR (Waste Form Qualification Report).

\subsection{Basic Functions of the Parts.}

\subsection{Canister Penetration system.}

This system allows the penetration of the stainless steel canister wall without cross-contamination of the internal gas of the canister with the outside atmosphere. The limit of the detection system is $10^{-4}$ Torr and the evacuated system must be able to generate a vacuum of $1 \mathrm{x}$ $10^{-3}$ Torr. In the penetration process, a vacuum will be attained, the system leak tested, and then the canister penetrated. (Mass spectral analysis should occur as soon as possible after measurement of the pressure and the relative humidity.)

\subsection{Pressure Sensor.}

A gauge (or gauges) which is capable of measuring pressure from 1 micron ( $10^{-4}$ Torr) to 1000 Torr will be required. The gauge should be calibrated prior to incorporation into the system. Calibration should also be checked after the experiments to ensure that it is still in calibration. A power supply for this device will be required. In addition a recorder will be required to record the pressure dependence as a function of time. 


\subsection{Relative Humidity Sensor}

A sensor will be required for the measurement of the relative humidity and dew point point temperature within the system. The Dew point temperature measurement should have a range between $-110^{\circ} \mathrm{C}$ to $+60^{\circ} \mathrm{C}$. The Panametrics Hygrometer, System I or II microprocessor-based moisture analyzer is acceptable. This system will have to be calibrated against NIST standards.

\subsection{Vacuum System.}

The vacuum system will allow for the evacuation of the penetration system. Hence, after breaching of the canister, the escaping gas from the canister will expand and be contained within the system without mixing with the outside atmosphere. A liquid nitrogen trap is required as part of this vacuum system to prevent back contamination of the system by the pump oil, to increase the vacuum, and to protect the pump from contamination. A vacuum pump with a free air displacement of 300 liters/ minute or better, a two stage design, and which can pull an ultimate vacuum of $1 \times 10^{-4}$ Torr is required (An example is the Varian SD-300 standard series mechanical pump). The liquid nitrogen cold trap should be connected in such a way that ready access for cleaning is possible.

\subsection{Connecting Port to the Mass Spectrometer}

A valve is required between the penetration system and the on-line mass spectrometer. After the canister has been breached, this valve will be opened. This line to the valve from the mass spectrometer side is already under vacuum from the vacuum system of the mass spectrometer. The diameter of the tube to the mass spectrometer may be $\sim 1 / 16$ to $1 / 4$ "O. D. The valves should be able to maintain the vacuum and not introduce contamination into the system.

\subsection{Valves, Fittings, and Plumbing}

A valve between the vacuum pump and the penetration system is essential. After evacuation of the penetration system, and just prior to breaching of the canister, this valve 
must be closed such that the air within the canister is not drawn into the pump. Another valve will be required between the penetration system and the mass spectrometer (see 4.5). Other valves may be required depending upon the final design. The valves should not interfere with the attainment of the $10^{-3}$ Torr vacuum and should not introduce contamination into the system. The total volume of the interconnecting plumbing should be kept as low as practical. This will minimize the pressure drop of the canister as a result of expansion into the system. The internal free volume of the canister is on the order of 110 liters.

Fittings for connecting the plumbing should be CAJON fittings. The tubing used in the penetration system should not introduce contamination into the system.

\subsection{Waste Disposal, Environmental Protection,} Permitting and other Regulatory Requirements.

These canisters will contain non-radioactive glass and a gas in the free volume which will be analyzed. This gas is mainly air, which will be released after analysis. It does not constitute an environmental hazard.

\subsection{Safety and Fire Protection Requirements.}

The SRL Safety Manual will be followed. The canister has been closed, but previous work has demonstrated that the internal pressure is actually less that atmospheric. During operation, the pressure gauge will indicate the pressure after penetration. If this pressure is greater than 1.3 atmospheres, the pressure will be released through the vacuum system. The penetration system includes electrically driven vacuum pumps and depending upon the design, other electrically driven components. Normal precautions such as grounding must be provided here.

\subsection{Raw Materials, Storage and Tank Farm Facilities.}

Not applicable. 
Not applicable.

\subsection{Service Facilities and Isolation}

\section{Requirements}

The canister shall be positioned horizontally. Electrical power will be needed for the pressure guage, vacuum pump and any other electrically driven components of the penetration system.

\subsection{Site and General Facilities}

Not applicable.

\subsection{Computer Requirements.}

Not applicable.

\subsection{Extra Machinery Spare Parts}

Extra parts as necessary should be fabricated. This includes any parts that may wear with time, or through use may cause the system to lose its leaktightness.

\subsection{Quality Assurance Requirements}

The procedures for Glass Technology (L13.1) on design will be followed. They are GT-QA-3-1,2 and 4 (all rev 2). The gauges should be considered Category $1 \mathrm{M} \& \mathrm{TE}$ and calibrated accordingly. The calibration records for the guages should be forwarded to John Harbour, 773-43A for eventual inclusion in the records package for these tasks. Data acquired using this system will be recorded in Laboratory Notebook, number yet to be assigned, according to the Glass Technology Procedures, GT-QA-2-7 (rev 2).

\subsection{Codes and Standards}

The leakrates of the modified canisters will be measured by qualified personnel using procedures in accordance with the 1989 Boiler and Pressure Vessel Code, ASME Section 5, article 10. Welding will be performed by qualified welders using procedures in accordance with ASME Boiler and Pressure Vessel Code, ASME Section 9. Critical welds 
shall be visually and dye penetrant tested with an acceptance criteria of AWS D1.1-90, section 8.15. In the case where a flange may have to be welded to the canister, the requirement is that a vacuum of $1 \times 10^{-3}$ Torr be reached.

\subsection{Decommissioning.}

This system will not be contaminated by use with these canisters. The parts, if borrowed from EES, will be returned after these experiments.

16.0 Appendices

None.

\section{0 keferences}

1. "Task Assignments and Requirements for Canister Testing and Archiving(U)", WSRC-RP-90-448, (1990) M. J. Plodinec.

2. "Compatibility of DWPF Canister and Contents, Task Assignment", WSRC-RP-8319, (1989) M. J. Plodinec.

3. "R/D Task Plan: Determination of the Relative Humidities within SRI Canistered Waste Forms", WSRC-RP-891354 (1989) J. R. Harbour.

4. "R/D Task Plan: Determination of the Pressure and Gas Composition within SRL Canistered Waste Forms", WSRC-RP-89-1355 (1989) J. R. Harbour.

5. "R/D Task Plan: Uiganic and Inorganic Analysis of Volatilized and Condensed Species within SRL Canistered Waste Forms", WSRC-RP-90-719 (1989) J. R. Harbour and C. M. Jantzen.

6. "The Determination of Pressure, Dewpoint, and Composition of the Gas Within the Free Volume of Canistered Waste Forms (U)" WSRC-RP-90-1167 (1990) J. R. Harbour, T. J. Miller, and M. J. Whitaker. 
1. $\because$

18.0 Figures

None

\section{AP PROVALS}

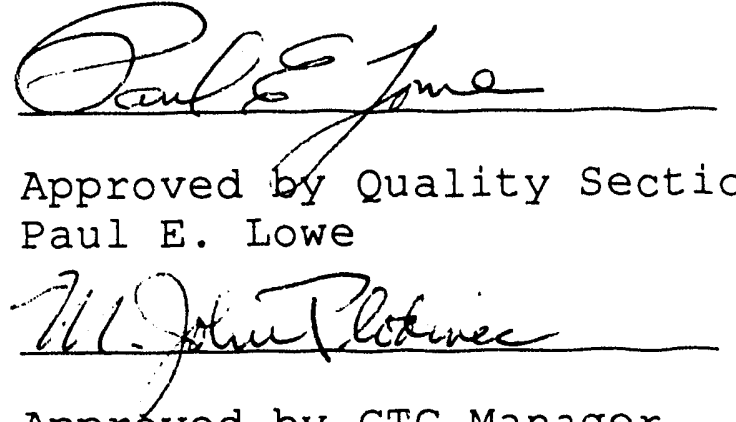

Approved by GTG Manager M. J. Plodinec

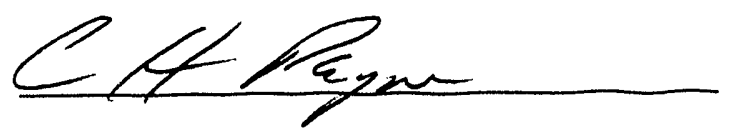

Approved by C. H. Payne, DWPE, Technical

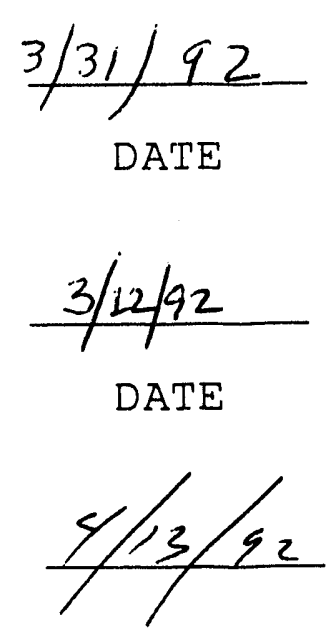

DATE 

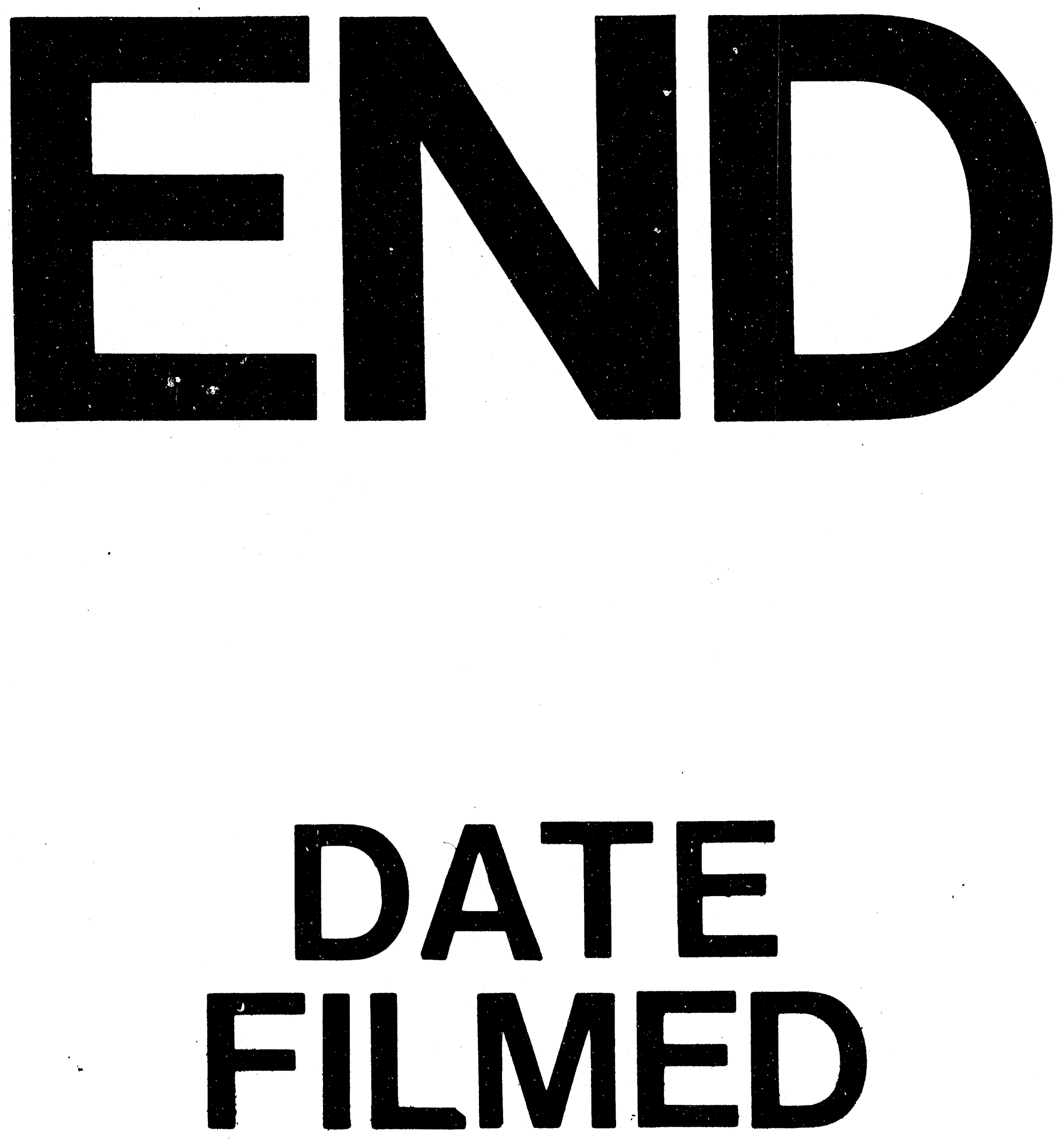

I

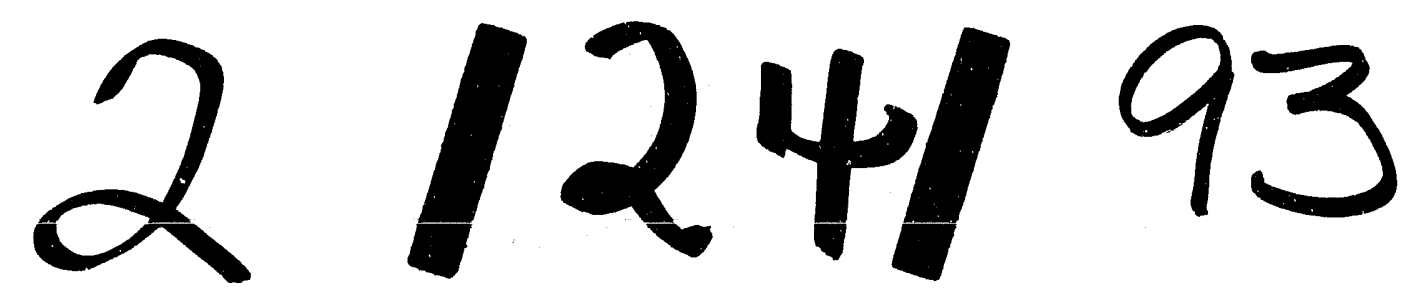


